\title{
State of Palliative Care Development in European Countries with and without Legally Regulated Physician-Assisted Dying
}

\author{
Jan L Bernheim ${ }^{1, *}$, Kenneth Chambaere ${ }^{1}$, Peter Theuns ${ }^{1,2}$, Luc Deliens ${ }^{1,3}$ \\ ${ }^{1}$ End-of-Life Care Research Group, VrijeUniversiteit Brussel (VUB) and Ghent University, Belgium \\ ${ }^{2}$ Methods in Psychology (MePs), Faculty of Psychology and Educational Science VrijeUniversiteit Brussel, Belgium \\ ${ }^{3}$ Palliative Care Center of Expertise, EMGO Institute for Health and Care Research VU University Medical Center, Amsterdam, the Nether- \\ lands \\ *Corresponding author (Email: jan.bernheim@vub.ac.be)
}

\begin{abstract}
In 2002 physician-assisted dying was legally regulated in the Netherlands and Belgium. Besides fundamental and ethical objections to physician-assisted dying, one of the frequently expressed pragmatic concerns is that legal regulation of physician-assisted dying, as implemented in the Netherlands and Belgium, could stunt the development of palliative care and erode its culture of competent and compassionate care. We here review these controversies and test the hypothesis that legal physician-assisted dying impeded the development of palliative care in the Netherlands and Belgium.

We collected the data over time on the funding of palliative care in Belgium. Next, using the data of the European Association for Palliative Care's 2007 Atlas of Palliative Care, we compared the state of development of palliative care in Western-European countries with and without legally regulated physician-assisted dying.

In Belgium, government expenditure for palliative care grew consistently by a yearly average of $10 \%$ over the 5 years following legal regulation of physician-assisted dying. As assessed in 2005, palliative care development in the Netherlands and Belgium did not lag behind Western-European countries without legally regulated physician-assisted dying, and was close to on a par with the UK, the benchmark country.

In conclusion, the hypothesis that legal regulation of physician-assisted dying stunts the development of palliative care is not supported by the Belgian and Dutch experience of the first several years. Continued monitoring of both permissive and non-permissive countries is needed to assess possible longer-term effects.
\end{abstract}

Keywords - Development of palliative care, jurisdictions with and without legal physician-assisted dying, the Netherlands, Belgium, European countries.

\section{Introduction}

Short review of the controversies raised by the Benelux countries' end-of-life legislations

Physician-assisted dying, i.e. physician-assisted suicide and euthanasia, the latter defined as ending a person's life at their explicit request, is in Europe legally regulated only in Belgium and the Netherlands since 2002 and Luxembourg since 2009. The legal conditions of prudence include an explicit and repeated request by a competent adult patient whose physical or mental suffering by an irreversible medical condition is "unbearable" and without any perspective of improvement. Also procedural precautions, including independent peer consultation, must be observed and cases must be reported to a review commission (Deliens \& van der Wal, 2003). The experience of the Benelux countries is under intense scrutiny, all the more because legally regulating physician-assisted dying is being debated in several other countries.
Can palliative care and physician-assisted dying be complementary, as posited for the Belgian model of end-of-life care(Bernheim, Deschepper, Distelmans, Mullie, Bilsen, \& Deliens, 2008), or are they incompatible? Several recent publications take the latter position, specifically challenging the Belgian construct of 'integral palliative care' and arguing that physician-assisted dying and palliative care are fundamentally antagonistic causes (Jaspers, Müller-Busch \& Nauck, 2009; Kettler \& Nauck, 2010; Johnstone, 2012; Materstvedt, 2012). The principled rejection of 'integral palliative care' is in line with traditional views in mainstream palliative care (Roy \&Rapin, 1994; Hamel, 1998; Mast, Salama, Silverman, \& Arnold, 2004; Meisel, 2005; Stephenson, 2006; Bosshard, Broeckaert,Clark, Materstvedt, Gordijn\& Müller-Busch, 2008). Indeed, the prevention of physician-assisted dying was one of the prime motivations of the founders of the palliative care movement (Saunders, 1976) and this tenet has remained widely endorsed ever since (Gordijn\& Janssens, 2000; 
Müller-Busch, Oduncu, Woskanjan, \& Klaschik, 2004).

Over and beyond such fundamental ethical stances, also pragmatic objections to legally regulated physician-assisted dying are frequently expressed, including the risks of slippery-slope effects and of erosion of public confidence in the healthcare services(Materstvedt et al., 2003; Finlay, Wheatley\& Izdebski, 2005; Gamester \& Van den Eynden, 2009; Pereira, 2011). The debate on these practical issues is ongoing. Epidemiological data from Oregon, the Netherlands and Belgium tend to allay these fears (Quill, 2007; Battin, van der Heide, Ganzini, van der Wal, \& Onwuteaka-Philipsen, 2007; Bernheim \& Mullie, 2010; Chambaere, Bilsen, Cohen, Onwuteaka-Philipsen, Mortier, \& Deliens, 2010, 2011; Downie, Chambaere \& Bernheim, 2012; Rietjens, Deschepper, Pasman, \& Deliens, 2012). While the epidemiological study results are hardly disputed, there are expressions of scepticism as to the validity of conclusions (Materstvedt, 2009) and criticisms of the imperfections in the enforcement of the Belgian law's prescriptions of prudence (Cohen-Almagor, 2013).

We here focus on a related, intellectually legitimate, pragmatic concern: the oft-invoked fear that legally regulated physician-assisted dying would impede the development of palliative care. This could happen if legally regulating physi- cian-assisted dying would erode the competent and compassionate care culture of palliative care, reduce demand for palliative care, draw attention and efforts away from palliative care and if governments would be tempted to save on scarce health-care resources by neglecting palliative care, thus nudging citizens and physicians towards the quick fix of physician-assisted dying (Saunders, 1976; Gordijn\& Janssens, 2000; Materstvedt et al., 2003; Finlay, Wheatley \& Izdebski, 2005; Gamester \& Van den Eynden, 2009; Pereira, 2011; Johnstone, 2012).

\section{Methods}

The hypothesis that legal regulation of physician-assisted dying could stunt the financial support of palliative care was investigated by seeking the governmental data on the funding of palliative care. These were found available only for Belgium (source details in the legend of Figure 1). Next, we compared the state of development of palliative care in European countries with and without legally regulated physician-assisted dying according to the indicators provided by the European Association for Palliative Care's Atlas of Palliative Care.

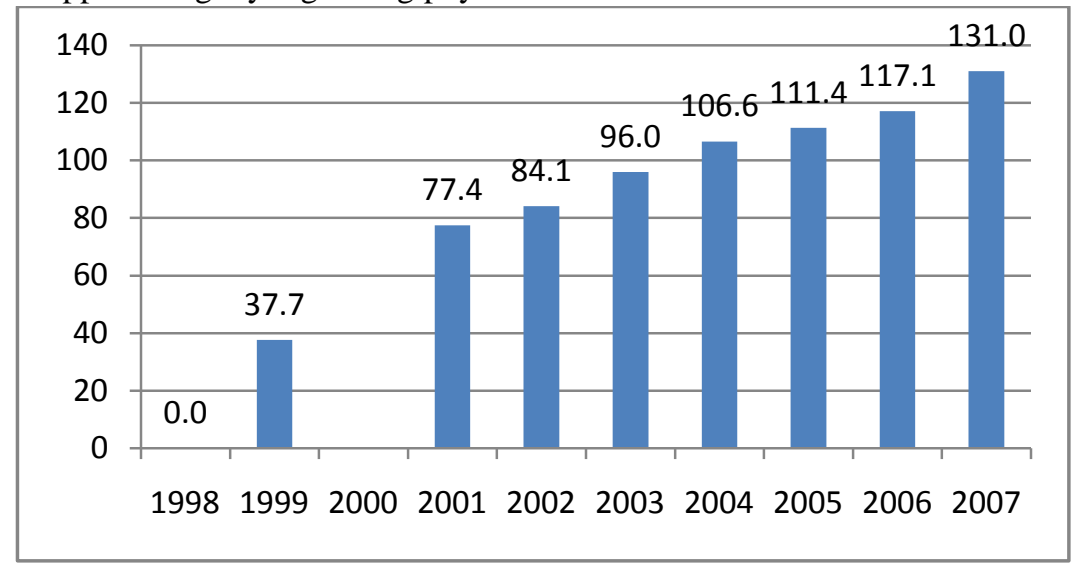

Figure 1. Total national expenditure on palliative care 1998-2007 (in million $€$ )

Source data 1999/2001: press communication by the Federal Secretary for Health in 2001: http://oud.frankvandenbroucke.be/html/soc/P-011029.htm (last accessed 13 June 2013), and converted from Belgian francs to Euros with the exchange rate of the introduction of the Euro in Belgium (1 EUR = 40.3399 Belgian francs).

Source data for federal expenditure for palliative care 2002-2007: Federal Evaluation Cell on Palliative Care. [Evaluation Report Palliative Care 2008] (in Dutch). Brussels: Federal Government Department Public Health, Food Safety and Environment, DG Organisation Health Care Services, Cell Chronic, Elderly and Palliative Care, 2008. Available at: http://www.health.belgium.be/internet2Prd/groups/public/@public/@dg1/@acutecare/documents/ie2divers/15720532.pdf (last accessed 13 June 2013).

Government expenditure is made up of funding of PC partnerships (federations and networks), PC at home (multidisciplinary support teams, reimbursement for palliative nursing, GP visits and physical therapy at home) and PC in hospitals (PCUs and PSTs) These figures exclude expenses for PC in day care centres and care homes, which are not available.

Data are inflation adjusted, using the World Economic Outlook (WEO) EconStats data, IMF: http://www.econstats.com/weo/V016.htm. (last accessed 13 June 2013).

Data for government expenditure in 2000 are lacking. In 1998 there was no government funding for PC, nor a reimbursement system for health care costs pertaining to PC.

The atlas is based on a survey of national experts and palliative care organisations carried out in 2005 by the EAPC Task Force on Palliative Care Development (Centeno et al., 2007 a \& b).As in the 2011 EAPC report to the UK Commission on Assisted Dying (Chambaere et al., 2011), we compared the available indicators of the state of development of

palliative care in four large Western European countries where physician-assisted dying is illegal (UK, France, Germany and Spain) with the Netherlands and Belgium. The five available structural indicators, which reflect the supply of services offered by professional palliative care to the public, are the per capita numbers of inpatient palliative care units 
and hospices, palliative care beds, support teams in hospitals, home-care palliative care services, and full-time palliative care physicians. The two available professional process indicators are the per capita rate of participation from each country in EAPC conferences as retrieved from EAPC records (EAPC congresses) andthe per capita number of PubMed publications per year, retrieved with the search string ("palliative care" OR "hospice care"). In a secondary analysis, for additional clarity, to better inform the debate on the putative inhibition of the development of palliative care by legally regulated physician-assisted dying, we ranked the countries involved for each indicator as well as on an index composed of all rankings.

\section{Results}

\subsection{The Belgian budget for palliative care before and since legal physician-assisted dying}

When in 2002 Belgium legally regulated physician-assisted dying, the passing of the law was preceded by a doubling of the federal budget for palliative care (Figure 1).

Support for this boost was unanimous because the merits of palliative care were undisputed and physician-assisted dying, for which legal regulation was then in preparation, was widely considered unethical if requested and carried out for lack of available professional palliative care. Concomitantly with the law on euthanasia, a law was enacted to ensure universal access to professional multidisciplinary palliative care (Bernheim et al. 2008). This law made palliative care a citizen's right, anticipating the Prague charter that was recently proposed by the European Association for Palliative care (EAPC) (Radbruch, de Lima, Lohmann, Gwyther, \& Payne, 2013). The total Belgian federal expenditure for palliative care, including the national health-insurance expenditure, has grown consistently by an annual average of almost $10 \%$ since the regulation of physician-assisted dying (Figure 1). This far exceeds the governmental norm for growth of health-care expenditure, which was $4.5 \%$ over inflation as of 2003 , but since 2013 stands at 2\% (Gerkens\&Merkur, 2010). Accordingly, Belgian palliative care has expanded considerably (Federal Evaluation Cell on Palliative Care, 2008). Only $10 \%$ of Belgian physicians think that the physician-assisted dying legislation was detrimental to the development of palliative care (Smets, Cohen, Bilsen, Van Wesemael, Rurup, \& Deliens, 2011).

\subsection{How does the level of development of palliative care in Belgium and the Netherlands compare with other European countries?}

Table 1. Rankings (\#) and scores (between brackets) of specific structural palliative care resources and scientific process indicators, per million inhabitants

\begin{tabular}{|c|c|c|c|c|c|c|}
\hline & $\begin{array}{c}\text { The } \\
\text { Netherlands }\end{array}$ & $\begin{array}{c}\text { Belgium } \\
\text { (Flanders) }\end{array}$ & $\mathbf{U K}$ & Spain & France & Germany \\
\hline \multicolumn{7}{|l|}{ Structural indicators $^{\mathrm{a}}$} \\
\hline 1) Inpatient units (PCUs and hospices) & $\# 1(5 \cdot 3)$ & \#2 (4.7) & \#3(3.7) & \#5 (2.2) & \#6 (1·3) & \#4 (3.0) \\
\hline 2) Palliative care beds & \#2 (43.9) & \#3 (34.8) & \#1 (53.1) & \#4 (25.3) & \#6 (26.6) & \#5 (24.6) \\
\hline 3) Palliative support teams in hospitals & \#4 (3·1) & \#1 (12.4) & $\# 2(5 \cdot 1)$ & \#5 (0.6) & \#3 (5.1) & \#6 (0.7) \\
\hline 4) Home care services & NA & \#3 (2.4) & \#1 (5.9) & $\# 2(3 \cdot 2)$ & \#4 (1.4) & \#5 (0.4) \\
\hline 5) Palliative care physicians (full time) & \#5 (0.6) & \#4 (2.3) & \#2 (7.4) & \#1 (11·3) & \#3 (6.0) & NA \\
\hline Mean rank for structural indicators & $3 \cdot 0$ & $2 \cdot 6$ & $1 \cdot 8$ & $3 \cdot .4$ & 4.4 & $5 \cdot 0$ \\
\hline Overall ranking for structural indicators & 3 & 2 & 1 & 4 & 5 & 6 \\
\hline \multicolumn{7}{|l|}{ Scientific and professional process indicators } \\
\hline 6) PubMed publications on palliative care $1991-2011^{\mathrm{b}}$ & $\# 1(55 \cdot 1)$ & $\# 2(45 \cdot 0)$ & \#3 (39.8) & $\# 6(8 \cdot 8)$ & \#5 (13.7) & \#4 (18.3) \\
\hline $\begin{array}{l}\text { 7) Average proportionate participation in EAPC confer- } \\
\text { ences }{ }^{c}\end{array}$ & $\# 2(0 \cdot 26)$ & $\# 1(0 \cdot 62)$ & \#3 (0.22) & $\# 4(0 \cdot 12)$ & \#5 (0.19) & \#6 (0.07) \\
\hline Mean rank for scientific and professional process indicators & $1 \cdot 5$ & $1 \cdot 5$ & 3 & 5 & 5 & 5 \\
\hline $\begin{array}{l}\text { Overall ranking for scientific and professional process } \\
\text { indicators }\end{array}$ & 1 & 1 & 2 & 3 & 3 & 3 \\
\hline \multicolumn{7}{|l|}{ Overall level of palliative care } \\
\hline Mean rank for all indicators & $2 \cdot 50$ & $2 \cdot 29$ & $2 \cdot 14$ & $3 \cdot 86$ & $4 \cdot 71$ & $5 \cdot 00$ \\
\hline Overall ranking & 3 & 2 & 1 & 4 & 5 & 6 \\
\hline
\end{tabular}

a source: EAPC Atlas of Palliative Care 2005 (Centeno et al., 2007)

bsource: Briefing paper from the EAPC (Chambaere et al., 2011b)

${ }^{\mathrm{c}}$ Mean \% participants per million inhabitants in the 12 research and general EAPC conferences between 2000 and 2011 (successively in Berlin, Palermo, Lyon, The Hague, Stresa, Aachen, Venice, Budapest, Trondheim, Vienna, Glasgow and Lisbon) according to the EAPC records (EAPC congresses)

$\mathrm{NA}=$ not available.

The per capita values of the indicators and the rankings of the countries are shown in Table 1 . The UK, where palliative care has the longest history, leads in terms of structural indicators, followed by Belgium and the Netherlands. If also the scientific and professional process indicators are taken into account, the two countries with legally regulated physician-assisted dying are found close to on a par with the UK, while a second cluster with a lesser overall level of palliative care development according to the available indicators comprises Spain, France and Germany.

\section{Discussion}

Strengths and imitations of the study

This study situates the issue of the development of palliative care among other controversies surrounding legally regulated 
physician-assisted dying in the Benelux countries. That our study is the first to rank European countries for level of supply of palliative care services, is a strength. Another strength is also considering the expenditure for palliative care, an important indicator, not only of structural availability of services to the public, but also of their output.

Our analysis has some limitations. For lack of criteria to do otherwise, we gave equal weights to all seven indicators though we recognise that, the organisation of palliative care being different between countries (Centeno et al., 2007a \& b), some indicators may be more important in one country than in another. Also, some relevant variables of output are at present available only for Belgium, including palliative care expenditure and the fraction of deaths preceded by professional multidisciplinary palliative care $(41 \%$ of all non-sudden deaths in 2007 as found by Van den Block et al., 2008). More robust conclusions will be possible when in the future such important indicators become available everywhere and also patient outcomes are taken into account. Also, importantly, for lack of measures of quality of care, we have dealt only with quantitative indicators.

The question whether the culture of competent and compassionate care has been affected in the Benelux countries is more difficult to answer with only quantitative data, which moreover lack patient outcome measures. However, clues that if anything it has improved can be inferred from statements by respected spokespersons for palliative care in Belgium. Palliative care workers who decline physician-assisted dying pledge to work hard at preventing such requests (Gamester \& Van den Eynden, 2009) and those who have endorsed physician-assisted dying state to practice it in the philosophy of 'integral palliative care', i.e. in the continuity of conventional palliative care, and with the same compassion (Bernheim et al. 2008; Bernheim \& Mullie, 2010).

\section{Conclusions}

This analysis, showing that in 2005 the physician-assisted dying-permissive countries were not lagging behind the non-permissive is in line with the EAPC report to the UK Commission on Assisted Dying (Chambaere et al., 2011) and earlier observations in Belgium (Bernheim et al., 2008), the Netherlands (Gordijn\& Janssens, 2004), and the USA (Lindsay, 2009). All suggested that legal regulation of assisted dying can be complementary with palliative care. Also in the Netherlands there is evidence that the legalisation of physician-assisted dying made the need for optimal palliative care more compelling, and boosted its development to its later high level (Janssens \& ten Have, 2001;Gordijn\& Janssens, 2004). However, whereas in Belgium the development of palliative care preceded and arguably enabled legal physician-assisted dying (Bernheim et al., 2008), the sequence and relationship appears to be inversed in the Netherlands: palliative care took off 'with a vengeance' after the 2002 law. All the evidence suggests that also in the physician-assisted dying-permissive countries the mainstream palliative care tenet of prevention of physician-assisted dying (Saunders, 1976) was an incentive to strengthen palliative care (Gordijn\& Janssens, 2000; Bernheim et al., 2008).

In sum, the here reviewed and generated evidence confirms that palliative care and legally regulated physician-assisted dying can coexist and be synergistic. The evidence from Belgium and the Netherlands during the first several years after the implementation of legally regulated physician-assisted dying does not verify the concern that the further development of palliative care would be stunted. However, some effects of legal physician-assisted dying on palliative care development may come to light only in the long run or in the form of phenomena that are not picked up by the currently available indicators. Therefore, there should be continued monitoring of both permissive and non-permissive countries, preferably also including patient outcomes.

\section{Keypoints}

- Both fundamental and pragmatic arguments are put forth against legally regulated physician-assisted dying, as since 2002 in Belgium and the Netherlands. A prominent pragmatic concern is the possible stunting of the development of palliative care.

- After the legalisation of physician-assisted dying, Belgium's expenditure for palliative care increased by an annual $10 \%$ and in 2005 the state of development of palliative care in the Netherlands and Belgium was close to on a par with the UK and ahead of the other non-permissive countries Spain, France and Germany.

- Well-developed palliative care may be a pre-requisite of legal regulation of physician-assisted dying, but may also be a consequence.

- Because effects of legal physician-assisted dying on palliative care development may manifest only later or in other ways, evolutions in both permissive and non-permissive countries should be further monitored.

\section{Acknowledgement}

Kenneth Chambaere is a Postdoctoral Fellow of the Research Foundation - Flanders. The Research Foundation has had no part in the writing of this manuscript or in the decision to submit it for publication. We thank TimoThibo and the EAPC Task Force on the Development of Palliative Care.

\section{References}

Battin, M. P., van der Heide, A., Ganzini, L, van der Wal, G., \& Onwuteaka-Philipsen, B. D. (2007). Legal physician-assisted dying in Oregon and the Netherlands: evidence concerning the impact on patients in "vulnerable" groups. Journal of Medical Ethics, 33, 591-597. 
Bernheim, J. L., Deschepper, R., Distelmans, W., Mullie, A., Bilsen, J., \&Deliens, L. (2008). Development of palliative care and legalisation of physician-assisted dying: antagonism or synergy? British Medical Journal, 336, 864-867.

Bernheim, J. L., \& Mullie, A. (2010). Physician-assisted dying and palliative care in Belgium: legitimate concerns and unsubstantiated grievances. Journal of Palliative Medicine, 13, 798-799.

Bosshard, G., Broeckaert, B., Clark, D., Materstvedt, L. J., Gordijn, B.,\& Müller-Busch, H. C. (2008). A role for doctors in assisted dying? An analysis of legal regulations and medical professional positions in six European countries. Journal of Medical Ethics, 34, 28-32.

Centeno, C., Clark, D., Lynch, T., Rocafort, J., Flores, L. A., Greenwood, A., Brasch, S., Praill, D., Giordano, A., \&De Lima, L. (2007a). EAPC Atlas of PC in Europe 2007. Available at: http://www.eapc-taskforce-development.eu/documents/taskforce/ATL AS-EAPC-2007.pdf

Centeno, C., Clark, D., Lynch, T., Racafort, J., Praill, D., De Lima, L., Greenwood, A., Flores, L. A., Brasch, S., Giordano, A., EAPC Task Force. (2007b). Facts and indicators on palliative care development in 52 countries of the WHO European region: results of an EAPC Task Force. Palliative Medicine. 21(6), 463-471.

Chambaere, K., Bilsen, J., Cohen, J., Onwuteaka-Philipsen, B. D., Mortier, F., \& Deliens, L. (2010). Physician-assisted deaths under the physician-assisted dying law in Belgium: a population-based survey. Canadian Medical Association Journal, 182, 895-901.

Chambaere, K., Bilsen, J., Cohen, J., Onwuteaka-Philipsen, B. D., Mortier, F., $\&$ Deliens, L. (2011a).Trends in medical end-of-life decision making in Flanders, Belgium 1998-2001-2007. Medical Decision Making, 31, $500-510$.

Chambaere, K., Centeno, C., Hernàndez, E., Van Wesemael, Y., Guillon-Grima, F., Deliens, L., \& Payne, S. (2011b). Briefing paper from the European Association for Palliative Care: Palliative Care Development in Countries with a Physician-assisted dying Law. Report for the Commission on Assisted Dying,submitted October 4th 2011. Available at: http://www.commissiononassisteddying.co.uk/publications (last accessed 6 October 2013).

Childress, J. (1998). Religious viewpoints. In: L. Emanuel (ed.). Regulating how we die. Ethical, medical and legal issues surrounding physician-assisted suicide. Cambridge, Harvard University Press, pp. 120-147.

Cohen-Almagor, R. (2013). First do no harm: pressing concerns regarding euthanasia in Belgium. International Journal of Law and Psychiatry. $36,(5-6), 515-521$.

Deliens, L., \& van der Wal, G. (2003). The physician-assisted dying law in Belgium and the Netherlands. Lancet, 362, 1239-1240.

Downie, J., Chambaere, K., \& Bernheim, J. L. (2012). Pereira's attack on legalizing physician-assisted dying or assisted suicide: smoke and mirrors. Current Oncololgy, 19, 133-138.

EAPC congresses: number of attendants and countries (webpage). Available from:

http://www.eapcnet.eu/Corporate/Events/Participantsbreakdown.aspx (last accessed 6 October 2013).

Federal Evaluation Cell on Palliative Care. (2008). Evaluatie Rapport Palliatieve Zorg [Evaluation report palliative care]. Brussels. Available at:

http://mailsystem.palliatief.be/accounts/15/attachments/rapporten/fed_ evaluatiecel_mai_2008_rapport_2008_nl.pdf (last accessed 6 October 2013).

Finlay, I. G., Wheatley, V. J., \& Izdebski, C. (2005). The House of Lords Select Committee on the Assisted Dying for the Terminally III Bill: implications for specialist palliative care. Palliative Medicine, 19, 444-53.

Gamester, N., \& Van den Eynden, B. (2009). The relationship between palliative care and legalized physician-assisted dying in Belgium. Journal of Palliative Medicine, 12, 589-591.

Gerkens, S. \& Merkur, S. Belgium: health system review. Healt Syst Transit 2010;12:1-266. Available from:

http://www.euro.who.int/_data/assets/pdf_file/0014/120425/E94245. PDF (last accessed 6 October 2013).
Gordijn, B., \& Janssens, R. (2000). The prevention of physician-assisted dying through palliative care: new developments in The Netherlands. Patient Education and Counseling, 41, 35-46.

Gordijn, B., \& Janssens, R. (2004). Physician-assisted dying and palliative care in The Netherlands: an analysis of the latest developments. Health Care Analysis 12, 195-207.

Hamel, R. (1998). A better approach to care of the dying. Catholic healthcare and the Catholic community can present an alternative to physician-assisted suicide. Health Progress, 79, 54-59.

Janssens, R.J., ten Have, H.A. (2001). The concept of palliative care in The Netherlands. Palliative Medicine 15, 481-486.

Jaspers, B., Müller-Busch, H., \& Nauck, F. (2009). Integral Palliative Care: a contradiction in terms? [in German] Zeitschrift für Palliativmedizin, 10, $162-166$.

Johnstone, M-J. (2012). Organization position statements and the stance of "studied neutrality" on physician-assisted dying in palliative care. Journal of. Pain and Symptom Management; 44, 896-907.

Kettler, D., \& Nauck, F..(2010). Palliative care and involvement of anaesthesiology: current discussions. Current Opinion in Anaesthesiology, 23, 173-176.

Lindsay, R.A. (2009). Oregon's experience: evaluating the record. American Journal of Bioethics, 9, 19-27.

Mast, K.R., Salama, M., Silverman, G.K., \& Arnold, R.M. (2004). End-of-life content in treatment guidelines for life-limiting diseases. Journal of Palliative Medicine, 7, 754-773.

Materstvedt, L.J., Clark, D., Ellershaw, J. Førde, R., Gravgaard, A.M., Müller-Busch, H.C., Porta i Sales, J., Rapin, C.H., \& EAPC Ethics Task Force. (2003). Physician-assisted dying and physician-assisted suicide: a view from an EAPC Ethics Task Force. Palliative Medicine, 17, 97-101.

Materstvedt, L. J. (2009). Inappropriate conclusions in research on assisted dying. Journal of Medical Ethics;35, 272.

Materstvedt, L. J. (2012). Palliative care ethics: the problems of combining palliation and assisted dying. Progress in Palliative Care. Online first 4 December 2012: http://www.ingentaconnect.com/content/maney/ppc/pre-prints/174329 $\underline{1 \mathrm{X} 12 \mathrm{Y} .0000000040}$

Meisel, A. (2005). Ethics and law: physician-assisted dying. Journal of Palliative Medicine, 8, 609-621.

Müller-Busch, H.C., Oduncu, F.S., Woskanjan, S., \& Klaschik, E.( 2004). Attitudes on physician-assisted dying, physician-assisted suicide and terminal sedation--a survey of the members of the German Association for Palliative Medicine. Medicine, Health Care and Philosophy, 7, $333-339$.

Pereira, J. (2011). Legalizing physician-assisted dying or assisted suicide: the illusion of safeguards and controls. Current Oncology, 18, 38-45.

Quill, T.E. (2007). Physician assisted death in vulnerable populations. British Medical Journal, 335, 625-626.

Radbruch, L., de Lima, L., Lohmann, D., Gwyther, E., \& Payne, S. (2013).The Prague Charter: urging governments to relieve suffering and ensure the right to palliative care. Palliative Medicine, 27, $101-102$.

Rietjens, J.A.C., Deschepper, R., Pasman, R., \& Deliens, L. (2012). Medical end-of-life decisions: does its use differ in vulnerable patient groups? A systematic review and meta-analysis. Social Science and Medicine, 74, 1282-1287.

Roy, J., \& Rapin, C. (1994). Regarding physician-assisted dying. European Journal of Palliative Care, 1, 57-59.

Saunders, C. (1976). Care of the dying--1. The problem of physician-assisted dying. Nursing Times, 72, 1003-1005.

Smets, T., Cohen, J., Bilsen, J., Van Wesemael, Y., Rurup, M.L., \& Deliens, L. (2011). Attitudes and experiences of Belgian physicians regarding physician-assisted dying practice and the physician-assisted dying law. Journal of Pain and Symptom Management, 45, 80-93.

Stephenson, J. (2006) Assisted dying: a palliative care physician's view. Clinical Medicine, 6, 374-377.

Van den Block, L., Deschepper, R., Bossuyt, N., Drieskens, K., Bauwens, S., Van Casteren, V., \& Deliens, L. (2008). Care for patients in the last months of life: the Belgian Sentinel Network Monitoring End-of-Life Care study. Archives of Internal Medicine, 168, (16),1747-1754. 